\title{
Urolithiasis: The Importance of the Post-Analytical Biochemical Process in Disease Diagnosis and Prevention
}

\author{
Fernández VG*, Sobrero MS, Brissón CM, Marsili NR, Bonifacino Belzarena R, Bartolomé J, Cuestas VI and Prono \\ Minella P
}

Facultad de Bioquímica y Ciencias Biológicas de la Universidad Nacional del Litoral, Argentina

*Corresponding author: Verónica G Fernández, Departamento de Bioquímica Clínica, Facultad de Bioquímica y Ciencias Biológicas, Universidad Nacional del Litoral, Santa Fe, Argentina

Submission: 眥 March 10, 2018; Published: 眥 April 05, 2018

\section{Opinion}

Urolithiasis is a pathology that has increased its incidence and prevalence in the last quarter of the 20th century. It is among the three most frequent urinary tract illnesses together with urinary infection and prostate benign disease [1], its recurrence rate being high as well [2]. Patients suffering urolithiasis need repeated hospital surgery and admission. Also, people who endure this disease are subject to repeated convalescence periods, being isolated from their routine activities and, in some cases, they even get to lose their kidneys unless they undergo the appropriate treatment. Its idiopathic origin is assumed in $50 \%$ of the cases [3]. However, multiple factors such as age, sex, race, diet, geography location, occupation, body mass index, among others, are associated with this disease [4].

After the first renal colic the main sanitary action is to anticipate disease reappearance, professional biochemist contributions being then relevant in diagnosis definition. For that purpose, it is necessary the determination of the underlying metabolic alteration that led to litho formation in the patient. Having the stone to analyze its composition would be the gold standard test to define such alteration. However, since many times the stone is not available, the analysis of blood and urinary metabolites associated with urolithiasis excreted in 24 hours must be carried out.

In order that a serious diagnosis is performed, the whole analytical process, in its pre-analytical, analytical and postanalytical stages, must be clear of any inacceptable error. Thus, the biochemist musteek to ensure a good collection, conservation and transportation of 24 hour urine carried out by the patient, make sure of result accuracy and be responsible for the Reference Values (RV) reported. The professional must verify commercial kit manufacturer RVs and evaluate their clinical accuracy in the population within the laboratory scope. This is crucial for urinary analytes, for if values from commercial inserts or bibliography are used instead, these values may correspond to populations with different diet, environmental and cultural standards, what, in turn, may lead to a wrong diagnosis. It is important to point out that RVs are also used in iterative programs evaluating urolithiasis risk.

The interdisciplinary research work performed at Universidad Nacionaldel Litoral (UNL), Santa Fe, Argentina, shows that urologists usually come across patients having recently had a renal colic. However, when the urinary metabolite study is carried out, results are found out to be within RVs. Two objectives have been planned in this study: a. to determine reference values corresponding to urinary analytes involved in urolithiasis in a population of biochemistry students at UNL, following the Clinical and Laboratory Standards Institute (CLSI) Document C28-A3 guideline [5].b. to evaluate clinical accuracy of the RVs found, of those reported by kit manufacturers, and of urinary indices. RVs determined for some analytes in urine matched those from the kits, there being no matching for some others [6]. When evaluating clinical accuracy by using Receiver Operating Characteristics (ROC) curves, it was found that both RVs corresponding to 24-hour excretions, determined according to the guideline, and RVs from manufacturers, showed excellent specificity, though sensitivity was lower than 50-60\%. Both situations would then explain what specialists noted "Results do not reflect the metabolic situation of patients undergoing a urolithiasis episode."

Currently, research continues by considering two approaches over the same population sample. On the one hand, it is evaluated the clinical accuracy of RVs determined by ROC analysis against those found by population distribution, following the (CLSI) Document C28-A3 guideline. On the other hand, the urinary index RVs which relate 24-hour excretions of urolithiasis promoters and those of inhibitors are established. Mid-term results show a remarkable improvement of sensitivity in both cases. For diagnosis and prevention of urolithiasis recurrences, the professional biochemist can make a relevant contribution by establishing the RVs according to the characteristics of the population within the laboratory scope and evaluating the clinical accuracy of the values obtained. 


\section{References}

1. Spivacow FR, del Valle EE, Negri AL, Fradinger E, Abib A, et al. (2015) Biochemical diagnosis in 3040 kidney stone formers in Argentina. Urolithiasis 43(4): 323-330.

2. Sánchez A, Sarano D, del Valle E (2011) Nefrolitiasis. Fisiopatología, evaluación metabólica y manejo terapéutico. Actual Osteol 7(3): 195234.

3. Arrabal Martín M, Fernández Rodríguez A, Arrabal Polo MA, Ruíz García MJ, Zuluaga Gómez A (2006) Estudio de factores físico-químicos en pacientes conlitiasis renal. Arch Esp Urol 59(6): 583-594.
4. Curham GC (2011) Epidemiology. In: Rao NP, Preminger GM and Kavanagh JP (Eds.), Urinary Tract Stone Disease. Springer, London, UK, pp. 3-7.

5. Wayne PA (2008) Clinical and Laboratory Standards Institute. Defining, establishing, and verifying reference intervals in the clinical laboratory: approved guideline - third edition. CLSI Document C28-A3.

6. Fernández V, Sobrero MS, Brissón C, Marsili N, Bonifacino Belzarena R, et al. (2017) Valores de referencia de oxalato, calcio, citrato, ácido úrico, fósforo, magnesio, sulfato y sodio urinarios en alumnos de la carrera de Bioquímica de la Universidad Nacional del Litoral, Argentina. RevNefrol Dial Traspl 37(3): 146-56.

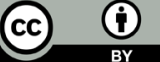

Creative Commons Attribution 4.0 International License

For possible submissions Click Here

\section{Submit Article}

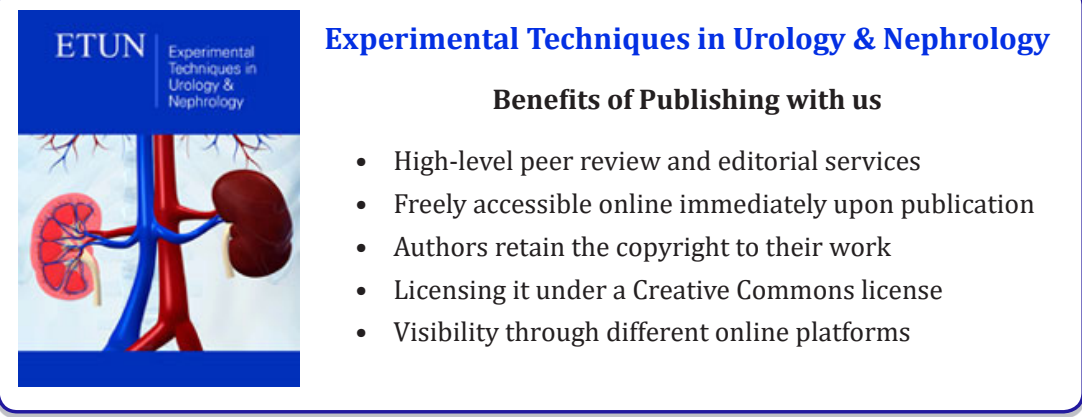

